\title{
The Theoretical Terrain of the Text: Reading Frame through The Edge of the Alphabet
}

\author{
JAN CRONIN \\ University of Leeds
}

Despite her recent appointment by the Arts Foundation as one of New Zealand's icons, talking or writing about Janet Frame still involves the risk of reifying her as ex-centric. Thankfully, the practice of resorting to Frame's well-known biographical details in order to explain the more challenging aspects of her fiction is now acknowledged as a reductive and ethically dubious process. However, such recourse to biography should also be seen as an instance of the critical desire for an interpretive matrix for Frame's work that persists today. The problem is that Frame's fiction perpetually gestures beyond such ready classifications as the postmodern, the postcolonial, and those paradigms offered by contemporary critical theory, making it tempting to agree with Keri Hulme that 'Janet is a stream entire unto herself'. 'The obvious danger of such sentiments is that they simply produce another version of the isolationist critical model of the past and leave Frame stranded in the rarified atmosphere of genius. This dilemma has proved the bane of more recent Frame criticism, which has delved into her texts rather than around and outside them. Despite Marc Delrez's uncomfortable inscription of his study of Frame's fiction in a postcolonial context, his 2002 book of close readings produced some of the keenest Frame related insights to date. ${ }^{2}$ The response in New Zealand Books was that: 'Delrez treats Frame's prose world as a self-enclosed system, albeit one which disallows the very idea of such solipsism'. ${ }^{3}$ What the reviewer, Jennifer Lawn, here identified as a central paradox in Delrez's work, in fact relates to a fundamental aspect of Frame's fiction, which Delrez reflected but only partially recognized. In Frame's fiction, there exists a distinction between the signification of her texts and the methodology of those same works, ${ }^{4}$ between the themes and concerns, which potentially unify and even inspire Frame's novels, and the modus operandi of the individual texts, which subsume and subvert those same concerns. This distinction is largely responsible for the inherent provisionality of Frame's texts, which frustrates generalisations and undermines attempts to consolidate a cohesive agenda for her fiction. This 
provisionality renders close readings of individual texts essential, just as the disjunction between the novels' signification and methodology indicates textual schemes that are sufficiently internally complex to warrant the kind of study that, even more so than Delrez's work, runs the risk of framing Frame as solipsistic.

In addition to the political and social components that have attracted so much critical attention over the years, Frame's texts are characterised by a preoccupation with abstracts and concepts, and have strong theoretical and philosophical components. Not only are her works philosophical in terms of subject matter, they are also highly theoretical in composition. Each Frame text comes equipped with its own theoretical terrain in which the narrative unfolds. Such contexts are often comprised of innovative refashionings, appropriations and destabilisations of pre-existing discourses such as Platonism, Patristic ideology, and Kantian philosophy. Hence, Frame can be construed as creating a self-contained fictional world while implicitly engaging with a history of ideas. However, it must said that although the origins of the dominant terms of many of her texts are then readily discernible, this alone offers no great insight into her work. What is significant is that obvious terms, such as the Kantian 'manifold' and the Platonic 'shadow', are removed from their original contexts and forged into alternate theoretical frameworks of Frame's design. This process then alerts the reader to the presence of other theoretical contexts in Frame's work, which are not dependent on reworkings of pre-existing materials, but which derive from the internal terms of the texts themselves. These theoretical contexts relate not only to enabling fusions of concepts and abstracts, but to the theoretical systems or structures which govern the substance of each text. The fact that these theoretical contexts are generated within the texts means that Frame's novels are theoretical in their composition rather than simply in their referencing or in their philosophical subject matter, and crucially, that her texts are fundamentally self-sufficient in nature.

This theoretical component of Frame's fiction is reflected in her oft-quoted remarks about the status of her texts as explorations rather than novels. Various exceptions to this have been mooted by Frame and others over the years, although the growing critical trend is to declare all of Frame's works fundamentally exploratory and fluidic in nature. ${ }^{5}$ Ultimately, there can be no authoritative critical version of Frame's fiction, as the natures of the respective texts are simply too diverse. What does seem apparent however, is that each of Frame's texts satisfies some condition or permutation within a critical matrix that consists of explorations, expositions, and theoretical contexts. The expositional aspects of certain Frame novels have been masked by the fluidity of the texts themselves and by the status of 'exploration' as a critical byword for Frame's fiction. An exposition entails a 
degree of enactment that is absent from an exploration; and that enactment endorses the conception of Frame's works as enclosed systems. One means of conceptualizing Frame's fiction is in terms of the archaic relationship between a thesis and its hypothesis, where the hypothesis constitutes a particular enactment, rather than an exploration, of a given thesis. This basic model is complicated by the fact that Frame's theses tend to be relatively simple, while the hypotheses or enactments are complex affairs, facilitated by, and partially comprised of, theoretical contexts.

Frame's third novel, The Edge of the Alphabet, ${ }^{6}$ exemplifies the case for the treatment of her texts as self-enclosed systems. Such treatment is by no means the last word in Frame criticism but it is a necessary step towards an appreciation of the complexity of Frame's texts. The Edge of the Alphabet presents a complicated version of the above account of Frame's work, and was initially regarded, as Frame put it, as 'unreadable in the worst sense'? Since then, in its infrequent critical encounters, it has been conscripted by the postcolonialists, who regard it as an 'intersection of different discourses of marginality', ${ }^{8}$ and more recently by proponents of a metaphysical brand of humanist Frame as 'evidence of eclipsed humanity'. ${ }^{9}$ The general tendency is for these and other readings to overlook the distinction between the signification and the modus operandi of Frame's work. ${ }^{10}$ That distinction initially manifests itself in The Edge of the Alphabet in a system whereby the novel's ostensible concerns, the integrity of individual identity and the mechanics of marginality, generate theoretical contexts which become the subject of the text. The theoretical terrain of the novel then derives not only from a deployment of external material, in this case Rainer Maria Rilke's Sonnets to Orpheus (1923), but also from the internal terms of the text, with the result that the novel operates as a self-sufficient system.

The Edge of the Alphabet is the first of Frame's texts to exhibit the fluidity and abstraction that characterize the current critical conception of the Framean exploration. Yet, as Michael King informs us in his biography of Frame, it "was the first of her books that she referred to from the outset as a novel, rather than "an exploration"." ${ }^{11}$ What is intriguing here is not so much the distinction between a novel and an exploration, but the fact that Frame disqualifies The Edge of the Alphabet as an exploration. This exclusion, it seems to me, is directly related to the status of the text as a complex configuration of thesis and hypothesis. About a third of the way through the novel, one of the characters refers to being 'shuttled over and under' (EA, p.78). Indeed, the most enabling way to conceptualize the text is in terms of a tapestry of uncertain pattern (the novel is ostensibly organized by an authorial figure named Pattern), the weaving and reading of which involves being 'shuttled over and under' in a variety of diverse directions. The thesis establishes the parameters of the tapestry, and inspires 
its content, while the hypothesis comprises the individual patterns within the tapestry, in other words, the substance of the text. Hence, however much the hypothesis resembles an exploration, it is ultimately an enactment, or exposition, of a fixed thesis. What makes The Edge of the Alphabet so complicated is that the thesis is not readily apparent, while the hypothesis is comprised of a myriad of shifting, fluctuating patterns, and the persistent annulment of distinctions between contexts and subjects, originals and analogies. What follows is a negotiation of The Edge of the Alphabet as a self-sufficient system. This account traces the modus operandi of the novel - the theoretical contexts that facilitate the hypothesis or substance of the text - until we emerge not at the inside or centre of the novel, but at the outside, at the motivating framework that is the novel's thesis.

The Edge of the Alphabet is ostensibly a metafictional exploration of identity, meaning and marginality. Against a backdrop of potential nuclear war and urban dystopia, Thora Pattern makes 'a journey of discovery' (EA, p.13) through what appear to be her three creations: New Zealander Toby Withers, Zoe Bryce from the English midlands, and Irishman Pat Keenan. The three characters meet mid-ocean on a voyage from New Zealand to England. Toby is the epileptic son from Frame's first novel, Owls do Cry, who, in this novel, travels overseas with his dream of turning his lauded school essay, 'The Lost Tribe', into a book of the same name. Zoe is a spinster teacher who pursued the reverse trajectory and went to New Zealand 'in search of what most people find in the next room or, closer, in the lining of their skin' (EA, p.77). En route back to England her search takes on a new dimension when she is kissed by an anonymous sailor as she lies in the ship's infirmary, and consequently enters an 'intensity of making' (EA, p.180). In contrast to these creative trials, Pat's journey to New Zealand was unfruitful because he failed to find the desired wife, and he now returns to England entrenched in his racism, Catholicism, and notions of the 'real' Ireland.

Any account of a Frame novel is at best partial. For all that is brought to light by one critical version, there is always more material awaiting other versions. In the above summary, character functions as a marker in a work that seems otherwise impossible to survey; for how does one survey a text that, as we shall see, consistently undermines the notion of mapping, and is designed to query the ordinance of patterning? How does one summarise a text that, in addition to patterning, seems in equal measure concerned with agency, alienation, apocalypse, art, authenticity, communication, death, dream, fiction, identity, individuality, language, marginality, meaning, memory, metafiction, migrancy, perception, and the past? For despite the journey motif and elements of a quest narrative, The Edge of the Alphabet does not chart a course of linear progression. Rather, the text is comprised 
of a series of fluctuating analogical patterns, which defy a progressive trajectory. Thora Pattern's facilitation, even potential production, of the novel is literalised in the status of pattern as the framework or context of the apparent explorations of the text. The novel's ostensible concerns, identity, agency etc., are posited in terms of patterns. For instance, Toby's marginality promotes 'a sense of gaps and holes and torn threadbare linings' (EA, p.24), and throughout the text, identities are treated as a series of beleaguered patterns. The Edge of the Alphabet operates by formulating a context of exploration, which literally subsumes the subjects of exploration, becoming itself the substance of the exploration. As Thora writes:

My interest is the maps of roads, underground cables, the terrible hoover that works here upon the stairs, sucking identities into the steel tube.

$(E A$, p.80)

In this way, the exploration of the authority and validity of patterning is established as foundational to the status and integrity of the more overt concerns of the text. If this switch between context and subject is not enough, Frame produces multiple theoretical contexts for the text by positioning those concerns (identity, marginality, metafiction etc.) as vehicles for that exploration of pattern. The result is that the novel's ostensible subjects are explored via expositions of patterns, while at the same time, those subjects are serving as expositions of the novel's exploration of patterning. Consequently, the novel functions on a system of analogical expositions, whereby multiple, horizontal versions of the exploration of patterning abound. This system of repetition and recapitulation lends a potentially subversive relentlessness to the work, and also renders the notion of conscious and unconscious enactment crucial. This system operates within a larger system of enactment, whereby the substance of the text, complete with its alternating theoretical contexts, constitutes the hypothesis of a given, albeit elusive, thesis.

As Thora Pattern is primarily concerned with the profound uncertainty regarding the possibility for meaningful patterns of existence, the concept of patterning and its attendant implications does indeed appear to be the central exploration of the text. This preoccupation sustains the novel's climate of uncertainty and occasional idealism. The result is a devotion to potentials, both positive and negative; in other words an ambidexterity that mimics the over and back of the weaving process. Editions of The Edge of the Alphabet gloss the text's direct quotations. While this still leaves a wealth of material unsourced (as befits the text's concerns with authenticity), it gives a good indication of the philosophical stances appropriated and reconfigured by Frame in the primary theoretical context, turned subject, of her novel. The majority of citations are from Rilke's Sonnets to Orpheus. Frame takes the 
basic elements of the sonnet sequence: 'What is life? What is the purpose of living? What is man's chief end?', ${ }^{12}$ and maintains the celebratory elements of that work in Thora's fragile idealism, while consistently challenging and undermining such convictions in the fluid fabric of the text. In an example of Frame's appropriation of source material, the ambidexterity within The Edge of the Alphabet constitutes a subversive revision rather than an endorsement of the Rilkean potential for harmonious duality. Many of the patterns within the tapestry of The Edge of the Alphabet depict the unravelling of Rilke's assertion:

Silken thread, you have entered into the weaving.

Feel, with what pattern soever you're inwardly blended

(even a scene from the story of Agony),

feel that the whole, the praisable, carpet's intended. ${ }^{13}$

The threat that motivates Thora Pattern is that the carpet is not intended, that the inward pattern is unrepresentable, while the 'whole' is a product of self-delusion.

The concept of patterning is invoked in the first verse section of the text, when Thora 'consider[s] the creatures who are beyond the range of words $[\ldots]$ the relics of the extinct monsters' (EA, p.22):

for in the shadow of conjectured bone

in the threadbare seam

uncovered between mantle and mantle of history we glimpse our own lives. (EA, p.23)

These stanzas exhibit a profound ambivalence towards patterns. The presence of patterns is at once a threat and a promise. A potentially transcendental pattern, designed by some unseen force, is reassuring as it confirms the existence of agency, and hence meaning, on some level. However, while we 'wrap' ourselves 'defensively' in the agency of 'an Outlandish Good Thing' ( $E A$, p.23), we ignore the risk that that same agency might (and, in the case of the dinosaurs, did) 'double-cross' (EA, p.22) its creation. The doublecross entails not only extinction, but the threat of meaninglessness, of being 'purposeless' (EA, p.22). Meaning is not discernible to those who comprise the pattern, and the absence of discernible meaning in turn deprives them of agency. Thus, on board the ship, Toby finds that absence of meaning confers fictional status, which robs him of self-determination:

- Am I fiction then, Toby wondered. Why should I share a cabin with an Irishman?

He trembled with suspicion and fear. Who was listening, who was recording the secret beating of his blood [ . . ] through his private body? $(E A$, p.52) 
Thora, allegedly the author of Toby's fiction, endures a version of his fear, of featuring in an inaccessible pattern, 'beyond the range of human language' (EA, p.23). She, however, is determined to apprehend patterns, 'to trace the compelling reason, the marginal dream', before it is too late, before 'our story is sealed at last' (EA, p.23). Thora is aware that this registers a tension between a potentially transcendental pattern and one of human delineation, and her determination is duly tempered by anxiety regarding the authenticity of these patterns. The act of tracing individual human patterns, such as those of Toby, Zoe and Pat, at once asserts and confounds agency; not simply in terms of the tension between the articulation of their perspectives and the resultant nullification of their agency by Thora, but in terms of the self-delusion attendant on Thora's apprehension of pattern, an apprehension that is the product of the 'human mind' (EA, p.23). The fear is literally one of fabrication, of false agency, of establishing oneself as a reader of a pattern, which may ultimately be the product of a self-delusional surveyor, just as:

the weather-vanes believe they trap the wind, as lilies on a snow-filled morning

imagine their whiteness is the sole reason. (EA, p.22)

This threat of self-deception is situated in the context of the larger threat that the 'Outlandish Good Thing' is potentially a transcendental fallacy, as is suggested by the 'deceived and dying' monster (EA, p.22). It is this set of anxieties regarding patterning that is perpetually rehearsed in the system of analogical expositions that comprises the hypothesis of the text. The most obvious example is found in the novel's exposition of fictional and metafictional states, and it is here that the sense of enactment first emerges.

Thora is ostensibly the author of the work:

Do I, Thora Pattern, imagine that I can purchase people out of my fund of loneliness and place them like goldfish in the aquarium of my mind's room and there watch them day and night swimming round and round kept alive by the titbits which I feed to them? (EA, p.113)

However, the novel capitalises on the nebulousness surrounding the status of the main three characters as 'people I have known, dreamed' (EA, p.208). As any actual pattern is subordinate to the concept and implications of patterning in the text, it is irrelevant whether or not Thora is the creator of these characters. What is important is that the climate of uncertainty is sustained by the potential patterns inscribed in that relationship. Implicit in Thora's seemingly unambiguous assertion of control is a proliferation of potential roles and relations: 
Lifelines of Toby Withers, Zoe Bryce, Pat Keenan, and others whom I have not yet named. Life-line, umbilical cord, fishing-line, trip-wire, strangling rope. (EA, p.163)

In The Edge of the Alphabet, that which is overstated is potentially being undermined. What appears to the reader as the metafictional pattern of the text, is compromised by the pervasive atmosphere of fictionality in Thora's allegedly created zone:

- What do you mean? Toby said angrily. - Have you been listening to my thoughts?

- No, it is just the paper walls, Zoe said wearily. (EA, p.103)

What appears as eavesdropping is posited, not in hierarchical terms, but as a sign of co-existence in the same fictional pattern. Thus, Thora's apparent status as eavesdropper casts aspersions on the ostensible metafictional pattern of the text, as her admission 'I hear your thoughts, Zoe' (EA, p.80) suggests a similar fictional co-existence between Thora and Zoe, to that of Toby and Zoe. The integrity of the metafictional pattern is further undermined by Thora's later injunction:

Be careful, take warning, the professional eavesdropper with the giant shears that reach from sky to earth and below and above is a sleepless creature; how words day and night; threads, ropes, wires, iron bands are defenceless against him, are snipped like spider-webs[.] (EA, p.185)

In comparison with this authority, Thora is the amateur eavesdropper. The references to the impotence of lines of words posit her as a false Atropos, undermining the apparent control in her earlier assertion of the potential ties between her and her alleged creations.

In place of a hierarchically derived metafictional pattern, the text presents the various fictional planes as versions of each other. Thora's characters enact a version of her predicament, namely, her anxiety regarding both her potential status within a pattern beyond her control and the potential absence of pattern altogether. In this way, Frame has constructed the substance of the text as a horizontal plane that consists of a series of enactments. This equation of fictional planes presents the obvious metafictional pattern of Thora as author as a paradigm akin to that of the weathervanes who believe they trap the wind' (EA, p.22). Such erosion of metafiction exemplifies the fear that resonates throughout The Edge of the Alphabet, that the perceived ordinance of patterning is a sham product of directionless creatures. Like the ageing homosexual Lawrence, whom Zoe observes later in the novel, Thora is ultimately:

one of those people who, because they have lost their bearings, have acquired a special interest and skill in being a compass for others, 
[ . . . ] You appear at crossroads, at the entrance to mazes, at the edge of the alphabet. [ . . . ] You do all this because [ . . ] you are confused, $[\ldots]$ because you are yourself homeless. (EA, p.198)

In keeping with this notion, the exploration of pattern implicit in the exposition of metafiction becomes entirely more menacing. This move is implicit in Thora's casting of the transcendental agency as an 'eavesdropper', a position the text has already compromised.

A minor figure in the text is that of Peter Heron, an artist later turned hire-purchase salesman. Towards the end of the text, Peter meets Zoe Bryce for the second time, and in response to her assertion that she does not know him, Peter echoes Thora's refrain 'I know you Zoe Bryce' (EA, p.153):

- But I know you, Zoe Bryce, [ . . . ] and Zoe blushed. He guesses, she thought. He guesses everything.

Then he frowned and sighed. - If only, he said. - My God, if only! (EA, p.198)

There is the suggestion here of a collision of fictional planes, of uncertain patterns and potential authorship, possibilities that are compounded by the note which precedes the body of the text:

The following manuscript was found among the papers of Thora Pattern after her death, and submitted to the publishers by Peter Heron, HirePurchase Salesman.

This note confounds the standard metafictional equation of the text. Not only does it posit the authorial figure in the same fictional array as her alleged characters, it also enacts the threat of the transcendental fallacy by suggesting that the author is the fiction of her own creation. This subversive metafiction rehearses Thora's fundamental fear, that the transcendental, the professional eavesdropper, is a figment of the desires of those who comprise potential patterns. Such a scenario threatens the existence of pattern, and hence meaningful existence. In their various responses, Thora and her characters are then enacting the final stanza of the second verse section of the novel:

we have gone back to the gap and the birth, the edge, where some leap in, others camp on the edge, incomplete with folding furniture $[\ldots]$ some shout or coo-ee God, God. (EA, p.48)

Thora's enactment of this stanza consists of an exploration of patterning which details the desire for the transcendental - in Rilkean terms: 'the longing to stand for one moment of [ . . ] life beneath the brilliance of the perfect circle' (EA, p.204). Attendant on such pursuits are the anxieties 
regarding the implications of the existence or absence of patterning for individuality, and the converse role of the individual in the apprehension of pattern. It is here that we see the complexity of the novel's theoretical contexts, as, in an inversion of the novel's analogical structure, that exploration of patterning then contextualizes the novel's concerns with the boundaries and integrity of individual identity.

Rilke instructs:

To the stock of used-up, as well as of dumb and decaying things within copious Nature, those sums beyond saying, count yourself joyfully in and destroy the account. ${ }^{14}$

Thora Pattern is concerned with the inarticulate 'peelings of $[\ldots]$ creation' $(E A, \mathrm{p} .13)$, and is preoccupied with the relationship between the individual and the rest of humanity; yet unlike the unreserved optimism of the Rilke sonnet, The Edge of the Alphabet is fraught with anxiety regarding the threat posed to agency and self by unity and community. In the final pages of the novel, Thora presents her version of Rilke's sonnet:

How I am haunted [ . . ] by the division of humanity into so many people when one birth, one mind, one death would be enough to end the tributary tears that flow in every acre of the earth in the stone obstructions of the heart that are called stars. What mathematical trick has divided the whole into the sum of so many people, only to set working in our hearts the process by which we continually strive to reduce the sum once more to its indivisible whole - until millions in one city become for us two or three people and finally one person. (EA, p.223)

Thora's references to illusion in the form of the 'mathematical trick', and subjective perception in the attribution 'for us', speak to the suspicion of the nature and origins of agency, and the threat of self-delusion, which resonate throughout the text. The apparent exploration of identity in The Edge of the Alphabet emerges from the anxiety generated by the text's sustained ambivalence regarding its status either as an enactment of the trick that divides the whole into the sum of its parts, via Thora's establishment of the characters 'as inheritors of my last will and testament, as if I bequeathed to them the parts of myself' (EA, p.208), or as a version of the process whereby the sum is traced to the inalienable whole through Thora's project of 'self-discovery' (EA, p.222). Crucially then, any exploration of identity is based on an exposition of pattern.

The Edge of the Alphabet sustains the tension between the desire to 'count oneself joyfully in' and the fear of 'destroy[ing] the account'. Analogous to this dynamic is the characters' perpetual oscillation between the desire for fluidity and fixity in their identities. Where conventional exclusionist 
patterns of society are a hindrance to authentic expressions of identity and individuality, an equally, if not more potent threat lies in the conflation and mergence of individual patterns. On the one hand, there is criticism of 'the pattern of people [that] trembles into place, outwardly harmless as a paper lantern, but fixed to the ceiling of desire, greed, longing' ( $E A, \mathrm{p} .59)$, yet on the other, there is dismay at the way 'people shift, like panels of lantern-slides or cards mysteriously removed and replaced, and one person is another, and people do not stay' (EA, p.35). In an analogical exposition of both the shifting patterns of identity and the implications of patterning, mirrors are unequivocally posited as instruments of subsumption. To mirror something is to erase its identity and individual integrity:

He looked for a mirror which would show himself, Toby Withers, his distinct identity; [ . . . ]

The mirrors had stolen his very shape, and rearranged it into something which did not belong to him any more. Why, he could even see [ . . . ] Pat Keenan [ . . ] and Zoe and her strange life and death. $(E A, \mathrm{p} .217)$

Yet versions or reflections are inscribed in both trajectories of exploration outlined above (the whole via the sum of the parts, or vice versa), and are fundamental to the composition of the text. Thus, in its perpetual versions, the text can be said to enact the substance of its own fears.

Zoe's replication of Thora's enterprise typifies this potentially perilous process of enactment. As with the text as a whole, Zoe's exploration, which is precipitated by the shipboard kiss, is difficult to chart. This is because, in an example of the text's analogical composition, her exploration is comprised of conflicting patterns of exposition, which are also versions of pre-existing expositions of pattern. Initially, the kiss is posited in terms of the transcendental: 'it was isolated from the pattern of Zoe's spinsterish life $[\ldots]$ it was, in a way a mythological act, [ . . ] an act beyond reason' (EA, p.88). This 'act beyond reason' recalls Thora's ambiguous 'Outlandish Good Thing' in the first verse section of the novel, and has an equally ambivalent relationship with patterns of existence. The apocalyptic properties of the kiss erase discernible, conventional patterns of identity:

And then she laughed aloud to think [ . . . that she had always believed [ . . . ] that people lived and died in shapes and identities with labels[.] (EA, p.86)

Rather than being simply anti-pattern however, the kiss occupies a series of fluctuating positions in versions of earlier pattern related paradigms.

The semblance of a transcendental act at once 'rocket[s] [Zoe] beyond meaning' (EA, p.74), yet, in an echo of Thora's fear of the nihilistic implications of the inaccessibility of transcendental patterns, it also makes 
her fiercely pursuant of meaning: 'The answer must mean something' (EA, p.74). Like Thora, Zoe then risks resembling the 'weather-vanes [who] believe they trap the wind' (EA, p.22). Implicit in this pattern is the erosion of the transcendental by the subjective; a scenario that segues into a further version of the text's metafictional exposition of the transcendental as a creation of the created:

My first kiss was isolated, detached, like a bloom which had parted from the stem and which I found lying unidentified and picked up without special responsibility to [ . . . ] graft upon my life[.] (EA, p.132)

Yet Zoe still paradoxically maintains that: 'The kiss is the core of my life [ . . . ] my meaning,' (EA, p.180). The status of the kiss then oscillates between transcendental act and subjective product. However, as Zoe finds, the plethora of potential patterns that the kiss implies is of an ambiguous source:

I can go to the Art Gallery and study the Kiss and its revelation in sculpture. I can come here and buy the facts of it. I am afraid. There are too many dimensions. (EA, p.189)

There is a pervasive uncertainty regarding the status of these dimensions as the issue of an inexorable subjectivity, the work of an apocalyptic transcendental, or as evidence of the absence of the transcendental altogether. This uncertainty effectively replicates Thora's concerns, combining as it does, Thora's earlier uncertainties regarding the patterns she alternately forges and/or traces in response to the potential absence or presence of the 'Outlandish Good Thing'.

In a direct echo of Thora's manifesto, Zoe declares herself:

interested now in traffic lanes, in byways, highways, in the terrible hoover at the top of the stairs, and the way my identity has been sucked in with the others so that in the dust and suffocation of the bag which contains us all I cannot tell my own particles, I am merely wound now with the others in an accumulation of dust - scraps of hair and bone welded in tiny golf-balls of identity to be cracked open, unwound, melting in the fierce heat of being. (EA, p.87)

This mimesis literalises and thereby undermines Zoe's reverential sense of the kiss as 'a kind of grafting process', whereby 'another world' is 'transferred' to her (EA, p.106). Zoe's exploration is then an ironic enactment of its own subject matter. As a version, it constitutes an unconscious exposition of worn material. Zoe elucidates Thora's predicament via this enactment, thereby rendering original and reflection indistinguishable, and further exemplifying Thora's concerns with unconscious erasure and subsumption. However, if Zoe's 'private research of identity' $(E A$, p.81) is 
rendered a pseudo-exploration by the ambivalence regarding her status as agent or vessel, her limitations cast aspersions on those of Thora, who is already preoccupied with the extent and integrity of individual autonomy and agency. Furthermore, Zoe's recycling of Thora's concerns draws attention to the central exploration of the text as less an exploration of pattern than an enactment of a pre-determined index of limitations. This suggests not only a distinction between Thora's enterprise and that of the text, but that we are emerging at the perimeter of the tapestry, the thesis.

The potential for a distinction between Thora's project and that of the text is further emphasized in the suggestion of the various creative efforts in the text as versions of each other. As with Zoe, there is some correlation between Thora's project and Toby's embryonic creativity. The fact that both relate to accounts of lost tribes has been taken as evidence of a humanist trajectory in the novel, whereby Thora achieves what Toby cannot. ${ }^{15}$ However, Thora's and Toby's projects are more similar than that paradigm allows. Toby's attitude to his 'Lost Tribe' enacts the text's pervasive fear of inclusion and communion as a form of erasure:

The Lost Tribe. No one but himself knew or understood the real meaning of it; no one possessed the subject as he did, and no one must ever share it. (EA, p.29)

More importantly, readings seeking excavations of 'eclipsed humanity' are playfully undermined, as Toby refuses to join 'a Society for Epileptics' in favour of 'his secret, his writing of the Lost Tribe' (EA, p.157). As we shall see, rather than Thora succeeding where Toby has failed in an evocation of community, Toby's 'Lost Tribe', like Zoe's so-called exploration, reflects Thora's own limitations.

Zoe's response to the destabilising effects of the kiss is: 'I must make something, quickly, recapture a shape, pin, hook, net the milling ocean - but oh my god!' (EA, p.87). What is interesting here is that this 'intensity of making' ( $E A$, p.180) is regarded not as the wages of the transcendental - the source of an authentic expression, or pattern of individuality - but as a desperate measure of compensation for the absence of these things. Toby's perpetual deferral of 'The Lost Tribe' is posited by Thora as the opposite of Zoe's trajectory:

Toby still dreams of the Lost Tribe. You and I know that he will never write it, that once he finds the real expression of it beyond the childhood story which the teacher read out in front of the class, he will be in as much danger as Zoe in her lonely wandering through the silver forest. (EA, pp.219-220)

Yet, as the context of Zoe's 'making' insists, the 'real expression' is one of compensation. Whether Zoe's suicide, upon completion of her work of art 
(the miniature silver forest forged from a silver cigarette wrapping), is an artistically enabling act of self-sacrifice, or the culmination of the pessimistic impulses of the novel, has long been a source of critical contention. ${ }^{16}$ Peter Heron's destruction of his canvas of 'the whole city [in] a shape of a magnified human finger-print' (EA, p.210), upon learning of Zoe's suicide, is an interpretation of Zoe's death as the culmination of the futility of communication and community. In this light, Zoe offers a nihilistic version of Thora, who is also partial to the notion 'that our code of measurement is singular, is not printed in anyone else's heart and cannot ever be shared' (EA, p.95), yet who still risks 'the fatal mistake of trying to communicate from so far on the edge of the alphabet' (EA, p.215). Like Zoe, publication of Thora's work necessitates her death, however this correlation signifies differently if we consider an alternate status for Zoe's death.

The limitations of Zoe's sculpture of the Silver Forest reflect the failures of those around her:

Here among the lonely people searching to appease their loneliness [...] Peter, the artist, dreaming of the painting which he will never complete (he also longing to stand for one moment of his life beneath the brilliance of the perfect circle), [ . . . ] here, have not I, Zoe Bryce, arrived at the time of my death? Has it not arisen with 'deliberate rightness'? (EA, p.204)

As an emblem of inevitable defeat, as an expression of the limits of compensation, 'the silver forest' is successful. This paradox is present in what is at once an indictment of the limitations of all communication and a devastatingly accurate explication of Zoe's suicide: 'Why need one write a note if one can communicate with a leftover wrapping of silver paper from an empty cigarette packet?' (EA, p.204). We then can see Zoe's suicide as the ultimate realisation of limitation, a limitation which, crucially, in a subversive deployment of a Rilkean notion, has a property of 'deliberate rightness'. ${ }^{17}$ Thora concedes the impotence of her own venture when she admits that, like Toby's non-existent version of 'The Lost Tribe', her version is ultimately an act of deferral: 'I must stop somewhere and begin my own life ... Is it true that self-discovery ends in death?' (EA, p.222). As her project then combines Toby's and Zoe's apparently contradictory strategies of deferral and confrontation, Thora's 'secret writing' (EA, p.222) can be conceived of as a poetics of deferral, which constitute an exposition of the 'deliberate rightness' or the inevitability of limitation. Such a project is necessarily comprised of fixed parameters, hence the paradox of the status of Thora's project as an articulation of the fluid perspective at the edge of the alphabet.

The notion of the edge of the alphabet is popular in postcolonial readings of Frame, as it lends itself readily to discourses of liminality and marginality. 
The problem is that the liminal and the marginal do not facilitate the fluid conception of the edge of the alphabet in Frame's novel, where the phrase relates to a perspective on oppositional possibilities:

the edge of the alphabet where words like plants either grow poisonous tall and hollow about the rusted knives and empty drums of meaning, or, like people exposed to a deathly weather, shed their fleshy confusion and show luminous, knitted with force and permanence. (EA, p.13)

In keeping with the philosophical nature and the theoretical framework of Frame's text, the edge of the alphabet is comprised of multiple potentials - in this example, positive and negative potentials for both the integrity of language, and the status of death. To say, as critics have said, that the novel promotes a dualistic artistic vision, ${ }^{18}$ is to ignore the fluidity attendant on these possibilities. Rather, the notion of the edge of the alphabet is predicated on ambidexterity, and as such constitutes the perspective that produces the fabric of the text. The weaving metaphor of being 'shuttled over and under' in alternating directions, provides a vital model of ambidexterity inscribed in a continuum. If dichotomies are then possibilities, which orient direction within potential patterns, the conditioning factor in these possibilities, and in the patterns of the novel, is the notion of 'beyond'.

What lies beyond the alphabet is central to Thora's various concerns with the transcendental. Death is posited as a 'plung[e] from the small cliff-area $[\ldots]$ at the edge of the alphabet' (EA, p.205). The second verse section of the text posits the possibility of 'God' over the edge, yet 'beyond the alphabet nothing has meaning, the letters are bracelets of the dead' (EA, p.112). The alphabet is a pattern that is of reason rather than 'beyond reason' (p.88, my italics), and is therefore distinct from the potentially transcendental, as sought by Thora. Thus, the notion of meaning is either rendered redundant or transcended, depending on the definition of death as either:

the vacant lot out of town, full of rusty sharp-edged tins, [ . . ] Or [ . . ] the oasis in the desert, with men constantly in search of it to build their homes and lives around it, that it may satisfy their hunger and thirst. Is it a pool which the years and their rotting vegetation have made stagnant but which in time can be freed to flow and irrigate our lives without the nightmare mosquito-sucking of our blood? (EA, pp.222-223)

As the status of death is of course dependent on the validity of the transcendental, resolution of these issues is perpetually deferred. This is played out in the dynamic of idealism and despair in Thora's work. In this way, the body of the text is an enactment of a series of potentials that are only articulated at the novel's conclusion.

It is only at the conclusion of the novel that the text's explorations emerge as expositions. It is at this point that we can look back at the substance of the 
text and see it clearly as a hypothesis in which the fluctuating significance of death, and other key concepts, destabilizes terms, and hence fluidizes patterns:

at the door of his dreams his dead mother was waiting with her little tray of poisonous apples.

The bracelet of decay glitters with diamonds. Tiny worms carry lanterns in the storm. At the edge of the alphabet there is no safeguard against the dead. (EA, p.16)

This passage depicts death as a resource, or alternatively light and treasure as deceptive measures, while the suggested alliance between dream, death and the edge of the alphabet amounts to a scale of possibilities, rather than an axis of marginality. Thus, the uncertainties regarding the potential for the transcendental, and the resulting implications for key concepts, promote a plethora of conflicting possibilities, which produce the fluctuating patterns of the hypothesis.

Crucially these patterns remain fundamentally inconclusive: "At the edge of the alphabet all streamers are torn or trail into strangeness' (EA, p.42). This inconclusivity, along with the uncertainty sustained by the pervasive ambidexterity of the terms of the text, is fundamentally at odds with what is a decidedly unsubtle work. In its perpetual versions, the text reiterates and overstates the same concerns. In its relentless rehearsals of fiction, identity, and marginality, even the most significant issues, such as the dynamic between inclusion and erasure, and the fictive analogies of existence, are rendered conceits, as they are perpetually re-represented rather than challenged or developed. The text is preoccupied with ambivalences regarding patterning, yet the patterns it undermines are those that it has deliberately established, thereby suggesting a calculated enactment of its own subject matter. The patterns present in the prolific discourse of identity are undone; the politics of displacement are sabotaged by Toby's abiding sense of the world as 'his private estate' (EA, p.156). Similarly, marginality, which is crucial to many accounts of the text, ${ }^{19}$ is revealed as a bogus element in an inaccessible pattern:

He died because he was a stranger, a foreigner from up north [ . . . ] he died because he was different, because he and his family had set up their camp apart, had not joined in [ . . . ] How else could they find meaning for his death? (EA, pp.166-167)

However, this taunting quotation also posits the pursuit of meaning, so central to the novel, as a litany of excuses. Thora's project is parodied in the gratuitous use of the term 'meaning' throughout the text and by the myriad speculations: 'What is the meaning of hunger?' (EA, p.178), 'What's the meaning of $[\ldots]$ creases in my shirt?' $(E A$, p.160). The text 
persistently enacts all the fallacies associated with such a pursuit, so that the myriad patterns that comprise the hypothesis (especially those relating to the exploration of patterning) are ultimately:

statements we put forth who are confused by so many causes dangling like powerful chains out of the sky, for us to swing upon (or hang ourselves) glittering with reason and explanation above the dark riddled seas of behaviour. (EA, p.183)

What this amounts to is fluidity inscribed in a context of fixed parameters (a version of the certainty of uncertainty, if you like); hence the tapestry motif. The patterns of the hypothesis are generated by a thesis which relates to the paradox of humanity's attempts to negotiate an index of limitations that is ultimately non-negotiable. The substance of the text is, as a result, an enactment of both those limitations and that paradox. In that early verse section, which seems to instigate Thora's exploration, she describes her enterprise as a bid 'to trace the compelling reason' within a context of deceit represented by the double-crossed dinosaur and the threat of pattern as a personal fabrication (EA, p.23). Thus, the inaccessible is sought, despite knowledge of its inaccessibility, and therein lies the paradox. Zoe demonstrates a similar awareness of the paradoxical nature of her pursuit when she muses:

My life has been sucked at last into the whirlpool, made shapeless as water, and here I am trying to carve it as if it were stone; and how beautiful is water which never shows the marks of age and decay! $(E A, \mathrm{p} .87)$

Thora's enterprise is then an enactment of the paradox that generates the text, in the same way that the other characters enact Thora's preoccupations. What for Thora is a compulsive, if ultimately self-delusional exploration, is, for the text, a foregone conclusion, an exposition.

The limitations which form the novel's thesis consist of the basic irresolvability of existential questions, and the inaccessibility of truth and meaning. In this way, Frame's thesis amounts to little more than an adolescent preoccupation with the meaning of life, yet the hypothesis which ensues is a rich, densely patterned, complex affair. It is this denseness that renders even the most comprehensive account of the text partial at best. It will hardly have gone unnoticed that the third character, Pat, is omitted in my reading of the text. This is because Pat belongs to another account of the novel, one which attends to the satirical aspects, and to an exploration of identity that is undoubtedly present in the text, but which, as we have seen, is also subordinate to a larger system of exposition, which renders such concerns meaningful conceits.

The potential for multiple readings of The Edge of the Alphabet then emerges from the difference between the immediate signification and the 
modus operandi of Frame's texts. It is this disparity that initially invites the reader to conceptualize Frame's work in terms of components of a self-enclosing system. To conceive of a text as a hypothesis is to reflect a distinction between what that text says and what it does. Elements of a hypothesis may signify independently of their context, yet they are also vehicles for something else; just as the expositions of pattern, identity and the attendant themes are all enactments of the relevant index of limitations in The Edge of the Alphabet. Rather than being a critical imposition, the notion of thesis and hypothesis reflects the closed system that is sponsored by the interplay of subject and theoretical context in that text. As a particular enactment of a thesis, a hypothesis presents a version of a specific subject. In the same way, the analogical structure of The Edge of the Alphabet offers a variety of alternate terms for its own matter, some of which derive from Rilke, but most of which are produced within the text. With such conscious representations of its own material, the text already gestures towards a process akin to the re-representation that is literary criticism.

To treat a text as a self-enclosed system is, ultimately, to respond to it on the terms on which it is based. To limit that response to the contexts inscribed in a text is obviously to run the risk of being reductive, but in the case of Janet Frame, whose textual contexts are so varied and complex, this approach has been neglected for too long. The notion of such criticism rendering the text solipsistic is countered by that very 'solipsism' then entailing an extension of the terms of appropriate critical response. The irony, exemplified by The Edge of the Alphabet, is that Frame's texts' selfconsciousness regarding their terms of representation inscribes a deliberate artifice in their hypothetical planes - something that becomes more explicit in the contextual revelations, especially those regarding ventriloquism, at the conclusions of Frame's later novels. Hence, tracing the modus operandi of a Frame text necessitates a degree of complicity in its conceits. To respond to a Frame novel 'on its own terms', is not only to willfully ignore the status of those terms as conceits, but to simultaneously make that willful ignorance explicit. In this way, there is potentially a homoeopathic remedy for Frame criticism, whereby like is treated with like, and criticism deploys the same modus operandi as the texts themselves, pursuing acts of avoidance that are ultimately acts of attention and vice versa.

1 Keri Hulme, interview with John Bryson, 24 Hours Supplement, January 1994, cited by Carole Ferrier (ed.), The Janet Frame Reader, London, 1995, p.11.

2 Marc Delrez, Manifold Utopia: The Novels of Janet Frame, Amsterdam, 2002.

3 Jennifer Lawn, 'Avoiding the Cookie-Cutter', in New Zealand Books, vol.13, no.3, August 2003, p.14. 


\section{Reading Frame through The Edge of the Alphabet}

4 Delrez recognizes a version of this distinction in what he terms 'the ultimate paradox' of Frame's pursuit of "an area of universal belonging" [ . . . ] via trajectories that remain entirely personal, even interiorized', p.xxix.

5 For example, Delrez, Manifold Utopia, and Gina Mercer, Janet Frame: Subversive Fictions, Dunedin, 1994.

6 Janet Frame, The Edge of the Alphabet, London, 1962. All subsequent in text references are to this edition.

7 Janet Frame to EP Dawson, cited by Michael King, Wrestling with the Angel: A Life of Janet Frame, Auckland, 2000, p.239. Frame was paraphrasing Norman Shrapnel, who accounted the novel 'a twilight essay in semi-coherence which, in no flattering sense, is extraordinarily difficult to read', 'Automatic Living', Guardian, 16/11/62, p.7.

8 Bill Ashcroft, Gareth Griffiths, Helen Tiffin, The Empire Writes Back: Theory and Practice in Post-colonial Literatures, London, 1989, p.104.

9 Delrez, Manifold Utopia, p.52.

10 The other main treatments of The Edge of the Alphabet are Patrick Evans's 'At the Edge of the Alphabet', in Jeanne Delbaere (ed.), The Ring of Fire: Essays on Janet Frame, Sydney, 1992, pp.82-91, and Gina Mercer's 'The Edge of the Alphabet, Journey: Destination Death', Australian and New Zealand Studies in Canada, no.5, Spring 1991, pp.39-57. Evans sees the novel as 'a parable about [Frame's] own artistic relationship to the world' (p.90), while Mercer's perspective combines elements of a humanist campaign with a non-postcolonial account of marginality and identity.

11 Janet Frame to Audrey Scrivener, 27/6/60, cited King, Wrestling with the Angel, p.220.

12 J.B. Leishman, introduction to Rilke's Sonnets to Orpheus, trans. by J.B. Leishman, London, 1946, p.31. This translation is generally considered to be the one used by Frame. All subsequent references to the Sonnets to Orpheus are to this edition.

13 Rilke, Sonnets to Orpheus, vol.II, no.XXI, 9-14, p.129.

14 Ibid., vol.II, no.XIII, 12-14, p.113.

15 Delrez, Manifold Utopia, p.61

16 For example, Evans, in Delbaere, The Ring of Fire, pp.88-90; Gina Mercer, 'Journey: Destination Death', pp.46-47.

17 Rilke, Sonnets to Orpheus, vol.II, no.XI, 1, p.109.

18 Evans, in Delbaere, The Ring of Fire, pp.83-84.

19 For example, Ashcroft, Griffiths \& Tiffin, The Empire Writes Back, pp.104-109; Gina Mercer, 'Journey: Destination Death', pp.39-57. 